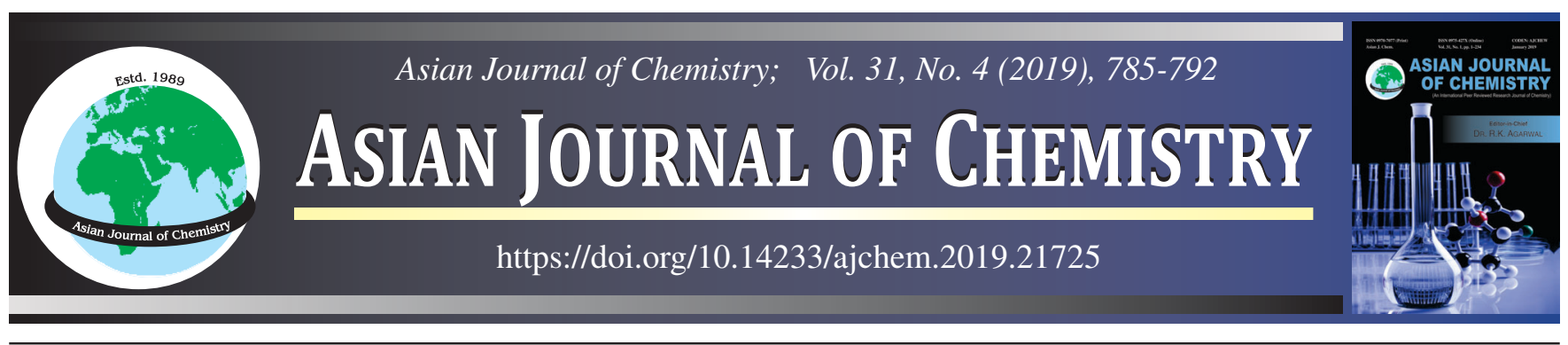

\title{
Microwave Assisted One-Pot Three-Component Synthesis of Novel Pyranocarbazole Derivatives as Antiproliferative Agents and Molecular Docking Studies
}

\author{
Bobbala Ramana Reddy* and Pedavenkatagari Narayana Reddy
}

Department of Chemistry, School of Technology, GITAM University, Hyderabad-502102, India

*Corresponding author: E-mail: bobbala.ramana91@gmail.com

Received: 25 September 2018;

Accepted: 29 November 2018;

Published online: 27 February 2019;

AJC-19286

A new series of pyrano[3,2-c]carbazole and pyrano[2,3- $a$ ]carbazole derivatives have been synthesized by one-pot three-component coupling
of 4-hydroxycarbazole or 2-hydroxycarbazole, aromatic substituted aldehydes and (E)-N-methyl-1-(methylthio)-2-nitroethenamine under
microwave irradiation. This transformation presumably occurs via Knoevenagel condensation-Michael addition-tautomerism intramolecular
O-cyclization-elimination sequence of reactions creating one C-O bond and two C-C bonds. The significant features of this one-pot
reaction include catalyst free, solvent free, atom-economy, no column chromatographic purification, short reaction time and good yield.
Further, the synthesized pyranocarbazole derivatives were evaluated for their antiproliferative activity against four cancer cell lines such
as DU 145 (prostate cancer), MDA-MB-231 (breast cancer), SKOV3 (ovarian cancer) and B16-F10 (skin cancer). The results clearly
demonstrated that trimethoxyphenyl substituted pyrano[3,2-c]carbazole (9h) exhibited most potent antriproliferative activity against
tested cell lines. Compounds $\mathbf{9 a}, \mathbf{9 b}$ and $\mathbf{1 1 a}$ were also displayed pronounced antriproliferative activity. In addition, molecular docking
studies revealed that the lead compounds bind to the colchicine binding site of the tubulin effectively. |

Keywords: Microwave, Pyranocarbazole, Antiproliferative, Molecular docking.

ᄂ - - - - - - - - - - - - - - - - - - - - - - - - - - - - - - - - -

\section{INTRODUCTION}

Carbazole is the central core of a large family of alkaloids [1-4] exhibiting promising biological activities such as antibacterial, antifungal, antitumor, anti-inflammatory, antihistaminic and neuroprotective properties [5-9]. Among these, pyranocarbazoles formed a prominent group due to their occurrence in various plants and useful biological activities including mosquitocidal, antimicrobial, anti-inflammatory and antioxidant activities [10,11].

Girinimbine (1) and isomahanine (3) have been reported to possess significant cytotoxicity against lung cancer (NCI522) [12-14], whereas, koenimbine (2) showed rapid scavenging activities against the 1,1-diphenyl-2-picrylhydrazyl radical [15]. Clausamines $\mathbf{4}$ and $\mathbf{5}$ have been reported to inhibit EBV activation in Raji cells [16-18]. Furthermore, pyranocarbazole derivatives have also used in the field of medicinal chemistry as a pharmacophore for different therapeutic indications.

The pharmacological potential of the pyranocarbazole derivatives has led to a strong interest in their synthesis and diverse synthetic methods have been developed [19-31]. Methods using domino aldol type/ $6 \pi$-electrocyclization, palladium catalyzed intramolecular C-O and C-C cross-coupling reaction [20] and iron-mediated oxidative cyclization [21] are common. Palladium(II)-catalyzed carbazole construction followed by pyran ring annulations [23,25-28], hexahydro-Diels-Alder reaction [32] and other methods have also been used [33-37]. Recently, we have developed a simple and efficient one-pot synthetic approach to pyrano[3,2-c]carbazole derivatives [38]. We also reported another approach for the synthesis of novel pyrano[3,2-c]carbazole derivatives via domino Knoevenagel-hetero-Diels-Alder reaction $[39,40]$. These derivatives showed significant anticancer activity by inhibiting tubulin polymerization. Recently, we utilized carbazole Mannich bases for the construction of pyrano[3,2c]carbazole derivatives via ortho-quinone methide formation [41]. Despite of these synthetic methods, development of new method for the diversity oriented synthesis of pyranocarbazoles from simple starting materials is of great interest.

Based on the important biological profile of pyranocarbazoles and our continuing interest on carbazole heterocycles

This is an open access journal, and articles are distributed under the terms of the Creative Commons Attribution-NonCommercial-ShareAlike 4.0 (CC BY-NC-SA 4.0) International License which allows readers to freely read, download, copy, distribute, print, search, or link to the full texts of its articles and to use them for any other lawful non-commercial purpose as long as the original source is duly acknowledged. 
[38-44], here we wish to report a new series of pyrano[3,2-c] and pyrano[2,3-a]carbazole derivatives by one-pot three component coupling reaction of 4-hydroxycarbazole or 2-hydroxycarbazole, aromatic substituted aldehydes and (E)-Nmethyl1-(methylthio)-2-nitroethenamine under microwave irradiation.

\section{EXPERIMENTAL}

All chemicals were purchased from Lancaster (Alfa Aesar, Johnson Matthey Co, Ward Hill, MA, USA), Sigma-Aldrich (St Louis, MO, USA) and Spectrochem Pvt Ltd (Mumbai, India). Reactions were monitored by TLC, performed on silica gel glass plates containing $60 \mathrm{~F}-254$ and visualization on TLC was achieved by UV light or iodine indicator. $1 \mathrm{H}$ NMR spectra were recorded on Avance (300 MHz); Bruker, Fallanden, Switzerland instruments. Chemical shifts were reported in ppm, downfield from internal TMS standard. ESI spectra were recorded on Micro mass, Quattro LC using ESI+ software with capillary voltage of $3.98 \mathrm{kV}$ and ESI mode positive ion trap detector.

General procedure for the preparation of compounds (9a-j and 11a-f): A mixture of 4-hydroxycarbazole (6) (1 mmol) or 2-hydroxycarbazole (10) (1 mmol), aromatic aldehydes (7) $(1 \mathrm{mmol})$ and (E)-N-methyl-1-(methylthio)-2-nitroethenamine (8) (1 mmol) were heated under microwave irradiation $(360 \mathrm{~W})$ for $5 \mathrm{~min}$. After completion of the reaction (confirmed by TLC), the reaction mixture was cooled to room temperature. The precipitated solid was filtered, washed with ethanol $(5 \mathrm{~mL})$ and dried to afford the pure products $9 \mathbf{a - j}$ or 11a-f (yields: 66$89 \%)$.

N-Methyl-3-nitro-4-phenyl-4,7-dihydropyrano[3,2c]carbazol-2-amine (9a): Pale brown solid. m.p. $>250{ }^{\circ} \mathrm{C}$; ${ }^{1} \mathrm{H}$ NMR (300 MHz, DMSO- $d_{6}$ ): $\delta 11.59$ (s, $1 \mathrm{H},-\mathrm{NH}-$ ), 10.61 (d, $1 \mathrm{H}, J=4.5 \mathrm{~Hz},-\mathrm{N} H-$ ), 8.25 (d, $1 \mathrm{H}, J=7.8 \mathrm{~Hz}, \mathrm{Ar}-H)$, $7.55(\mathrm{~d}, 1 \mathrm{H}, J=8.1 \mathrm{~Hz}, \mathrm{Ar}-H), 7.45(\mathrm{t}, 1 \mathrm{H}, J=8.1 \mathrm{~Hz}, \mathrm{Ar}-H)$, 7.37-7.20 (m, 7H, Ar-H), 7.15 (d, $1 \mathrm{H}, J=6.9 \mathrm{~Hz}, \mathrm{Ar}-H)$, 5.49 (s, 1H, - CH-), 3.47 (d, 3H, $\left.J=4.8 \mathrm{~Hz},-\mathrm{CH}_{3}\right) ;{ }^{13} \mathrm{C}$ NMR $\left(75 \mathrm{MHz} \mathrm{CDCl}_{3}\right)$ : $\delta 159.1,145.4,141.9,140.0,139.7,128.3$, $127.2,126.3,126.1,125.7,122.1,119.7,119.3,114.0,111.2$, 109.9, 108.7, 108.2, 41.1, 28.9; ESIMS: m/z $372(\mathrm{M}+\mathrm{H})^{+}$; HRMS: $m / z(\mathrm{M}+\mathrm{H})^{+}$calcd. for $\mathrm{C}_{22} \mathrm{H}_{18} \mathrm{~N}_{3} \mathrm{O}_{3}: 372.1403$, found: 372.1408 .

4-(4-Fluorophenyl)- $N$-methyl-3-nitro-4,7-dihydropyrano[3,2-c] carbazol-2-amine (9b): Dark brown solid. m.p. 218-220 ${ }^{\circ} \mathrm{C}$; ${ }^{1} \mathrm{H}$ NMR (300 MHz, DMSO- $\left.d_{6}\right): \delta 11.59$ (s, $1 \mathrm{H}$, $-\mathrm{N} H-$ ), 10.60 (d, $1 \mathrm{H}, J=4.8 \mathrm{~Hz},-\mathrm{N} H-), 8.24$ (d, $1 \mathrm{H}, J=7.8$ $\mathrm{Hz}, \mathrm{Ar}-H), 7.55$ (d, $1 \mathrm{H}, J=8.7 \mathrm{~Hz}, \mathrm{Ar}-H), 7.45(\mathrm{t}, 1 \mathrm{H}, J=7.5$ $\mathrm{Hz}, \mathrm{Ar}-H), 7.41-7.21$ (m, 5H, Ar-H), 7.06 (t, 2H, J=8.7 Hz, $\mathrm{Ar}-H), 5.52$ (s, $1 \mathrm{H},-\mathrm{CH}-), 3.46\left(\mathrm{~d}, 3 \mathrm{H}, \mathrm{J}=4.8 \mathrm{~Hz},-\mathrm{CH}_{3}\right)$; ${ }^{13} \mathrm{C}$ NMR $\left(75 \mathrm{MHz}, \mathrm{CDCl}_{3}\right): \delta 159.0,141.9,141.6,141.6$, 140.0, 139.7, 129.2, 129.1, 126.2, 125.8, 122.1, 119.7, 119.4, 115.1, 114.8, 75 113.8, 111.2, 109.9, 108.8, 108.1, 41.1, 28.9; ESIMS: $m / z, 390(\mathrm{M}+\mathrm{H})^{+}$; HRMS: $m / z(\mathrm{M}+\mathrm{H})^{+}$calcd. for $\mathrm{C}_{22} \mathrm{H}_{17} \mathrm{~N}_{3} \mathrm{O}_{3} \mathrm{~F}$ : 390.1117, found: 390.1122 .

$\mathrm{N}$-Methyl-3-nitro-4-(3-nitrophenyl)-4,7-dihydropyrano[3,2-c] carbazol-2-amine (9c): Pale brown solid. m.p. 185$187{ }^{\circ} \mathrm{C} ;{ }^{1} \mathrm{H}$ NMR $\left(300 \mathrm{MHz}, \mathrm{DMSO}-d_{6}\right): \delta 11.62(\mathrm{~s}, 1 \mathrm{H}$, $-\mathrm{N} H-), 10.64$ (d, $1 \mathrm{H}, J=5.1 \mathrm{~Hz},-\mathrm{N} H-), 8.26$ (d, 2H, $J=8.7$ $\mathrm{Hz}, \mathrm{Ar}-H), 8.04$ (d, 1H, $J=8.4 \mathrm{~Hz}, \mathrm{Ar}-H), 7.78$ (d, $1 \mathrm{H}, J=$
$7.8 \mathrm{~Hz}, \mathrm{Ar}-H), 7.68-7.35$ (m, 3H, Ar-H), 7.32-7.22 (m, 3H, $\mathrm{Ar}-H), 5.73$ (s, 1H, -CH-), 3.48 (d, 3H, J = 4.5 Hz, $-\mathrm{CH}_{3}$ ); ${ }^{13} \mathrm{C} \mathrm{NMR}\left(75 \mathrm{MHz}, \mathrm{CDCl}_{3}\right): \delta 159.1,158.9,145.4,141.9$, 140.0, 139.8, 128.2, 126.2, 125.8, 122.2, 119.7, 119.3, 119.0, 114.0, 113.8, 111.2, 111.0, 109.9, 108.9, 108.1, 41.1, 28.9; ESIMS: $m / z \quad 417(\mathrm{M}+\mathrm{H})^{+}$; HRMS: $m / z(\mathrm{M}+\mathrm{H})^{+}$calcd. for $\mathrm{C}_{22} \mathrm{H}_{17} \mathrm{~N}_{4} \mathrm{O}_{5}$ : 417.1912, found: 417.1919.

4-(2-(Methylamino)-3-nitro-4,7-dihydropyrano[3,2c]carbazol-4-yl)benzonitrile (9d): Dark brown solid. m.p. 188-190 ${ }^{\circ} \mathrm{C} ;{ }^{1} \mathrm{H}$ NMR (300 MHz, DMSO- $\left.d_{6}\right): \delta 11.62$ (s, $1 \mathrm{H}$, -NH-), 10.63 (d, 1H, J = 4.5 Hz, -NH-), 8.24 (d, 1H, J = 7.5 $\mathrm{Hz}, \mathrm{Ar}-H), 7.73(\mathrm{~d}, 2 \mathrm{H}, J=8.1 \mathrm{~Hz}, \mathrm{Ar}-H), 7.54(\mathrm{t}, 2 \mathrm{H}, J=8.1$ $\mathrm{Hz}, \mathrm{Ar}-H), 7.46(\mathrm{t}, 1 \mathrm{H}, J=7.5 \mathrm{~Hz}, \mathrm{Ar}-H), 7.36-7.20$ (m, 4H, $\mathrm{Ar}-H), 5.61$ (s, 1H, $-\mathrm{CH}-$ ), 3.47 (d, 3H, $\left.J=4.8 \mathrm{~Hz},-\mathrm{CH}_{3}\right)$; ${ }^{13} \mathrm{C} \mathrm{NMR}\left(75 \mathrm{MHz}, \mathrm{CDCl}_{3}\right): \delta 159.1,155.8,145.4,141.9$, 140.0, 139.8, 135.6, 128.2,126.2, 125.7, 125.5, 125.2, 125.0, 122.2, 119.7, 119.3, 113.2, 111.3, 109.9, 108.9, 108.1, 41.0, 28.9; ESIMS: $m / z 397(\mathrm{M}+\mathrm{H})^{+}$; HRMS: $m / z(\mathrm{M}+\mathrm{H})^{+}$calcd. for $\mathrm{C}_{23} \mathrm{H}_{17} \mathrm{~N}_{4} \mathrm{O}_{3}$ : 397.1801, found: 397.1805 .

N-Methyl-3-nitro-4-(4-(trifluoromethyl)phenyl)-4,7dihydropyrano[3,2-c]carbazol-2-amine (9e): Pale brown solid. m.p. $>250{ }^{\circ} \mathrm{C} ;{ }^{1} \mathrm{H}$ NMR (300 MHz, DMSO- $d_{6}$ ): $\delta 11.61$ (s, 1H, -NH-), 10.63 (d, 1H, J = 4.8 Hz, -NH-), 8.25 (d, 1H, $J=7.8 \mathrm{~Hz}, \mathrm{Ar}-H), 7.72-7.55(\mathrm{~m}, 5 \mathrm{H}, \mathrm{Ar}-H), 7.46(\mathrm{t}, 1 \mathrm{H}, J=$ $7.5 \mathrm{~Hz}, \mathrm{Ar}-H), 110$ 7.38-7.20 (m, 3H, Ar-H), 5.62 (s, 1H, $-\mathrm{CH}-$ ) 3.47 (d, 3H, J =5.1 Hz, $\left.-\mathrm{CH}_{3}\right) ;{ }^{13} \mathrm{C}$ NMR $(75 \mathrm{MHz}$, $\left.\mathrm{CDCl}_{3}\right): \delta 158.9,150.8,150.1,141.9,140.1,139.7,128.2$, 126.1, 125.8, 125.3, 125.2, 125.2, 122.2, 119.7, 119.4, 112.9, 111.2, 109.9, 108.9, 107.6, 41.0, 29.0; ESIMS: $m / z 440(\mathrm{M}+\mathrm{H})^{+}$; HRMS: $m / z(\mathrm{M}+\mathrm{H})^{+}$calcd. for $\mathrm{C}_{23} \mathrm{H}_{17} \mathrm{~F}_{3} \mathrm{~N}_{3} \mathrm{O}_{3}$ : 440.1405, found: 440.1412 .

4-(2-(Methylamino)-3-nitro-4,7-dihydropyrano[3,2c]carbazol-4-yl)phenol (9f): Dark brown solid. m.p. $>250$ ${ }^{\circ} \mathrm{C}$; ${ }^{1} \mathrm{H}$ NMR $\left(300 \mathrm{MHz}, \mathrm{DMSO}-d_{6}\right): \delta 11.56(\mathrm{~s}, 1 \mathrm{H},-\mathrm{NH}-)$, 10.57 (d, 1H, $J=4.8 \mathrm{~Hz},-\mathrm{NH}-), 9.20$ (s, 1H, -OH), 8.23 (d, $1 \mathrm{H}, J=7.8 \mathrm{~Hz}, \mathrm{Ar}-H), 7.54(\mathrm{~d}, 1 \mathrm{H}, J=7.8 \mathrm{~Hz}, \mathrm{Ar}-H), 7.45(\mathrm{t}$, $1 \mathrm{H}, J=7.8 \mathrm{~Hz}, \mathrm{Ar}-H), 7.36-7.18(\mathrm{~m}, 3 \mathrm{H}, \mathrm{Ar}-H), 7.07$ (d, 2H, $J=8.1 \mathrm{~Hz}, \operatorname{Ar}-H), 6.62(\mathrm{~d}, 2 \mathrm{H}, J=8.1 \mathrm{~Hz}, \operatorname{Ar}-H), 5.37$ (s, $1 \mathrm{H},-\mathrm{CH}-$ ), 3.45 (d, 3H, $\left.J=4.8 \mathrm{~Hz},-\mathrm{CH}_{3}\right) ;{ }^{13} \mathrm{C} \mathrm{NMR}(75 \mathrm{MHz}$, $\left.\mathrm{CDCl}_{3}\right): \delta 159.1,155.8,145.9,141.9,139.8,139.7,135.8$, 128.2, 126.2, 125.7,122.1, 119.7, 119.3, 115.0, 114.7, 113.8, 111.2, 108.7, 108.1,41.1, 28.9; ESIMS: $m / z 388(\mathrm{M}+\mathrm{H})^{+}$; HRMS: $m / z(\mathrm{M}+\mathrm{H})^{+}$calcd. for $\mathrm{C}_{22} \mathrm{H}_{18} \mathrm{~N}_{3} \mathrm{O}_{4}$ : 388.1303 , found: 388.1307 .

4-(3-Methoxyphenyl)-N-methyl-3-nitro-4,7-dihydropyrano[3,2-c] carbazol-2-amine (9g): Dark brown solid. m.p. 218-220 ${ }^{\circ} \mathrm{C}$; ${ }^{1} \mathrm{H}$ NMR (300 MHz, DMSO- $\left.d_{6}\right): \delta 11.58(\mathrm{~s}, 1 \mathrm{H}$, -NH-), 10.60 (d, 1H, J = 4.8 Hz, -NH-), 8.25 (d, 1H, J = 7.5 $\mathrm{Hz}, \mathrm{Ar}-H), 7.54(\mathrm{~d}, 1 \mathrm{H}, J=8.1 \mathrm{~Hz}, \mathrm{Ar}-H), 7.45$ (t, $1 \mathrm{H}, J=7.8$ $\mathrm{Hz}, \mathrm{Ar}-H), 7.38-7.20$ (m, 3H, Ar-H), 7.15 (t, $1 \mathrm{H}, J=8.1 \mathrm{~Hz}$, Ar-H), 6.92 (s, 1H, Ar-H), 6.83 (d, 1H, J = 7.5 Hz, Ar-H), $6.72(\mathrm{~d}, 1 \mathrm{H}, J=7.8 \mathrm{~Hz}, \mathrm{Ar}-H), 5.47$ (s, 1H, -CH-), 3.70 (s, $\left.3 \mathrm{H},-\mathrm{OCH}_{3}\right), 3.46\left(\mathrm{~d}, 3 \mathrm{H}, \mathrm{J}=4.8 \mathrm{~Hz},-\mathrm{CH}_{3}\right) ;{ }^{13} \mathrm{C}$ NMR $(75$ $\left.\mathrm{MHz} \mathrm{CDCl}_{3}\right): \delta 159.2,159.1,147.0,141.9,140.0,139.7$, 129.5, 126.1, 125.7,122.1 119.7, 119.3, 119.2, 113.9, 113.7, 111.2, 111.0, 109.9,108.7, 108.0, 54.9, 41.0, 28.9; ESIMS: $m / z 402(\mathrm{M}+\mathrm{H})^{+}$; HRMS: $m / z(\mathrm{M}+\mathrm{H})^{+}$calcd. for $\mathrm{C}_{23} \mathrm{H}_{20} \mathrm{~N}_{3} \mathrm{O}_{4}$ : 402.1213, found: 402.1216 . 
$N$-Methyl-3-nitro-4-(3,4,5-trimethoxyphenyl)-4,7dihydropyrano[3,2-c]carbazol-2-amine (9h): Dark brown solid. m.p. $>250{ }^{\circ} \mathrm{C} ;{ }^{1} \mathrm{H}$ NMR $\left(300 \mathrm{MHz}, \mathrm{DMSO}-d_{6}\right): \delta 11.12$ (s, $1 \mathrm{H},-\mathrm{N} H-), 10.75(\mathrm{~d}, 1 \mathrm{H}, J=4.5 \mathrm{~Hz},-\mathrm{N} H-), 8.25(\mathrm{~d}, 1 \mathrm{H}$, $J=7.5 \mathrm{~Hz}, \mathrm{Ar}-H), 7.57(\mathrm{~d}, 1 \mathrm{H}, J=8.1 \mathrm{~Hz}, \mathrm{Ar}-H), 7.45(\mathrm{t}, 2 \mathrm{H}$, $J=7.8 \mathrm{~Hz}, \operatorname{Ar}-H), 7.30(\mathrm{~m}, 3 \mathrm{H}, \mathrm{Ar}-H), 7.21(\mathrm{~d}, 1 \mathrm{H}, J=7.5$ $\mathrm{Hz}, \mathrm{Ar}-\mathrm{H}), 5.47$ (s, $1 \mathrm{H},-\mathrm{CH}-), 3.79$ (s, 9H, $\left.-\mathrm{OCH}_{3}\right), 3.76$ (d, $\left.3 \mathrm{H}, J=4.8 \mathrm{~Hz},-\mathrm{CH}_{3}\right) ;{ }^{13} \mathrm{CNMR}\left(75 \mathrm{MHz}, \mathrm{CDCl}_{3}\right): \delta 159.2$, 159.1, 145.4, 141.9, 140.1, 139.9, 139.7, 128.3, 127.1, 126.2, 125.8, 122.8, 122.0, 119.8, 119.1, 113.8, 111.2, 109.9, 108.5, 108.0, 58.6,54.9, 41.1, 28.9; ESIMS: $m / z 462(\mathrm{M}+\mathrm{H})^{+}$; HRMS: $m / z(\mathrm{M}+\mathrm{H})^{+}$calcd. for $\mathrm{C}_{25} \mathrm{H}_{24} \mathrm{~N}_{3} \mathrm{O}_{6}: 462.1604$, found: 462.1611 .

4-(4-Isopropylphenyl)- $N$-methyl-3-nitro-4,7-dihydropyrano[3,2-c] carbazol-2-amine (9i): Dark brown solid. m.p. $178-180{ }^{\circ} \mathrm{C} ;{ }^{1} \mathrm{H}$ NMR $\left(300 \mathrm{MHz}\right.$, DMSO- $\left.d_{6}\right): \delta 11.57(\mathrm{~s}, 1 \mathrm{H}$, $-\mathrm{N} H-), 10.59(\mathrm{~d}, 1 \mathrm{H}, J=4.8 \mathrm{~Hz},-\mathrm{NH}-), 8.25(\mathrm{~d}, 1 \mathrm{H}, J=7.5$ $\mathrm{Hz}, \mathrm{Ar}-H), 7.54(\mathrm{~d}, 1 \mathrm{H}, J=7.8 \mathrm{~Hz}, \mathrm{Ar}-H), 7.45(\mathrm{t}, 1 \mathrm{H}, J=7.2$ $\mathrm{Hz}, \mathrm{Ar}-H), 7.35-7.17$ (m, 5H, Ar-H), $7.10(\mathrm{~d}, 2 \mathrm{H}, J=8.1 \mathrm{~Hz}$, $\mathrm{Ar}-H), 5.46(\mathrm{~s}, 1 \mathrm{H},-\mathrm{CH}-), 3.46$ (d, $\left.3 \mathrm{H}, J=4.8 \mathrm{~Hz},-\mathrm{CH}_{3}\right)$, $2.79\left(\mathrm{~m}, 1 \mathrm{H},-\mathrm{CH}\left(\mathrm{CH}_{3}\right)_{2}\right), 1.13\left(\mathrm{~s}, 3 \mathrm{H},-\mathrm{CH}_{3}\right), 1.11(\mathrm{~s}, 3 \mathrm{H}$, $\left.-\mathrm{CH}_{3}\right) ;{ }^{13} \mathrm{C}$ NMR $\left(75 \mathrm{MHz}, \mathrm{CDCl}_{3}\right): \delta 159.1,154.3,153.9$, $146.4,142.8,139.9,139.7,128.3,127.1,126.2,125.8,122.8$, 122.2, 119.7,119.4, 115.0, 114.3, 111.2, 108.8, 108.1, 40.7, 33.0, 29.0, 23.8; ESIMS: $m / z 414(\mathrm{M}+\mathrm{H})^{+}$; HRMS: $m / z(\mathrm{M}+\mathrm{H})^{+}$ calcd. for $\mathrm{C}_{25} \mathrm{H}_{24} \mathrm{~N}_{3} \mathrm{O}_{3}$ : 414.1509, found: 414.1514.

$\mathrm{N}$-Methyl-3-nitro-4-(pyridin-3-yl)-4,7-dihydropyrano[3,2-c]carbazol-2-amine (9j): Pale brown solid. m.p. 238$240{ }^{\circ} \mathrm{C} ;{ }^{1} \mathrm{H}$ NMR $\left(300 \mathrm{MHz}, \mathrm{DMSO}-d_{6}\right): \delta 11.62(\mathrm{~s}, 1 \mathrm{H}$, $-\mathrm{N} H-$ ), 10.63 (d, $1 \mathrm{H}, J=4.5 \mathrm{~Hz},-\mathrm{N} H-), 8.64$ (s, $1 \mathrm{H}, \mathrm{Ar}-H$ ), $8.36(\mathrm{~d}, 1 \mathrm{H}, J=7.5 \mathrm{~Hz}, \mathrm{Ar}-H), 8.25(\mathrm{~d}, 1 \mathrm{H}, J=7.5 \mathrm{~Hz}, \mathrm{Ar}-$ $H$ ), $7.55(\mathrm{~d}, 1 \mathrm{H}, J=7.8 \mathrm{~Hz}, \mathrm{Ar}-H), 7.46(\mathrm{t}, 1 \mathrm{H}, J=7.5 \mathrm{~Hz}$, $\mathrm{Ar}-H$ ), 7.40-7.20 (m, 3H, Ar-H), 7.19-7.00 (m, 2H, Ar-H), $5.55(\mathrm{~s}, 1 \mathrm{H},-\mathrm{CH}-), 3.47\left(\mathrm{~d}, 3 \mathrm{H}, J=4.5 \mathrm{~Hz},-\mathrm{CH}_{3}\right) ;{ }^{13} \mathrm{C} \mathrm{NMR}$ (75 MHz, $\mathrm{CDCl}_{3}$ ): $\delta$ 164.5, 161.8, 159.1, 145.4, 141.9, 140.0, 139.7, 128.3, 127.3, 126.2, 125.7,122.1, 119.7, 119.3, 114.0, 111.2, 109.9, 108.7, 108.2, 41.1, 28.9; ESIMS: m/z 373 $(\mathrm{M}+\mathrm{H})^{+}$; HRMS: $m / z(\mathrm{M}+\mathrm{H})^{+}$calcd. for $\mathrm{C}_{21} \mathrm{H}_{17} \mathrm{~N}_{4} \mathrm{O}_{3}: 373.2143$, found: 373.2152 .

$\mathrm{N}$-Methyl-3-nitro-4-phenyl-4,11-dihydropyrano[2,3a] carbazol-2-amine (11a): Dark brown solid. m.p. 190-192 ${ }^{\circ} \mathrm{C}$; ${ }^{1} \mathrm{H}$ NMR (300 MHz, DMSO- $\left.d_{6}\right): \delta 11.41$ (s, $1 \mathrm{H},-\mathrm{NH}-$ ), $10.38(\mathrm{~d}, 1 \mathrm{H}, J=4.5 \mathrm{~Hz},-\mathrm{NH}-), 8.08(\mathrm{~d}, 1 \mathrm{H}, J=7.8 \mathrm{~Hz}, \mathrm{Ar}-$ $H$ ), 7.46(d, $2 \mathrm{H}, J=7.8 \mathrm{~Hz}, \mathrm{Ar}-H), 7.42-7.32$ (m, $2 \mathrm{H}, \mathrm{Ar}-H$ ), 7.30-7.00 (m, 5H, Ar-H), 5.89 (s, $1 \mathrm{H},-\mathrm{CH}-), 3.25(\mathrm{~d}, 3 \mathrm{H}, J=$ $\left.4.8 \mathrm{~Hz},-\mathrm{CH}_{3}\right) ;{ }^{13} \mathrm{C} \mathrm{NMR}\left(75 \mathrm{MHz}, \mathrm{CDCl}_{3}\right): \delta 159.1,145.4$, 144.4, 142.2, 139.1, 131.0, 128.7, 126.6, 125.7, 123.5, 122.5, 119.7, 119.3,115.3, 111.2, 109.9, 108.2, 98.3, 41.1, 28.9; ESIMS: $m / z, 372(\mathrm{M}+\mathrm{H})^{+}$; HRMS: $m / z(\mathrm{M}+\mathrm{H})^{+}$calcd. for $\mathrm{C}_{22} \mathrm{H}_{18} \mathrm{~N}_{3} \mathrm{O}_{3}: 372.1373$, found: 372.1379 .

4-(4-Bromophenyl)- $N$-methyl-3-nitro-4,11-dihydropyrano[2,3-a]carbazol-2-amine (11b): Dark brown solid. m.p. $212-214{ }^{\circ} \mathrm{C} ;{ }^{1} \mathrm{H}$ NMR $\left(300 \mathrm{MHz}\right.$, DMSO- $\left.d_{6}\right): \delta 11.41$ (s, $1 \mathrm{H},-\mathrm{NH}-), 10.38$ (d, 1H, $J=4.5 \mathrm{~Hz},-\mathrm{NH}-), 8.10(\mathrm{~d}, 1 \mathrm{H}, J$ $=7.8 \mathrm{~Hz}, \operatorname{Ar}-H), 7.45(\mathrm{~d}, 1 \mathrm{H}, J=7.8 \mathrm{~Hz}, \mathrm{Ar}-H), 7.42-7.30$ (m, 4H, Ar-H), 7.28-7.00 (m, 4H, Ar-H), 5.88 (s, $1 \mathrm{H},-\mathrm{CH}-$ ), $3.23\left(\mathrm{~d}, 3 \mathrm{H}, J=5.1 \mathrm{~Hz},-\mathrm{CH}_{3}\right) ;{ }^{13} \mathrm{C} \mathrm{NMR}\left(75 \mathrm{MHz}, \mathrm{CDCl}_{3}\right)$ : $\delta$ 159.0, 145.4, 143.5, 142.6, 141.4, 139.1, 128.7, 125.7, 123.5, $122.5,122.2,119.5,119.0,118.8,115.5,111.4,109.3,108.1$,
98.5, 41.0, 28.9; ESIMS: $m / z 451(\mathrm{M}+\mathrm{H})^{+} ;$HRMS: $m / z(\mathrm{M}+\mathrm{H})^{+}$ calcd. for $\mathrm{C}_{22} \mathrm{H}_{17} \mathrm{~N}_{3} \mathrm{O}_{3} \mathrm{Br}$ : 451.2141, found: 451.2149.

$\mathrm{N}$-Methyl-3-nitro-4-(4-nitrophenyl)-4,11-dihydropyrano[2,3-a]carbazol-2-amine (11c): Dark brown solid. m.p. $180-182{ }^{\circ} \mathrm{C}$; ${ }^{1} \mathrm{H}$ NMR $\left(300 \mathrm{MHz}, \mathrm{DMSO}-d_{6}\right): \delta 11.65(\mathrm{~s}$, $1 \mathrm{H},-\mathrm{NH}-), 10.60(\mathrm{~d}, 1 \mathrm{H}, J=4.5 \mathrm{~Hz},-\mathrm{NH}-), 8.12(\mathrm{~d}, 1 \mathrm{H}, J=$ $7.8 \mathrm{~Hz}, \mathrm{Ar}-H), 7.48$ (d, $1 \mathrm{H}, J=7.6 \mathrm{~Hz}, \mathrm{Ar}-H), 7.43-7.35$ (m, $3 \mathrm{H}, 100 \mathrm{Ar}-H), 7.28-7.10$ (m, 5H, Ar-H), 5.81 (s, $1 \mathrm{H},-\mathrm{CH}-$ ), $3.30\left(\mathrm{~d}, 3 \mathrm{H}, J=4.8 \mathrm{~Hz},-\mathrm{CH}_{3}\right) ;{ }^{13} \mathrm{C} \mathrm{NMR}\left(75 \mathrm{MHz}, \mathrm{CDCl}_{3}\right): \delta$ 159.1,148.5, 145.2, 141.9, 141.1, 139.3, 129.2, 128.5, 125.7, 124.8,123.5, 122.2, 119.5, 119.3, 115.1, 111.1, 109.5, 107.1, 108.4,98.3, 41.4, 28.7; ESIMS: $m / z 417(\mathrm{M}+\mathrm{H})^{+}$; HRMS: $\mathrm{m} / z$ $(\mathrm{M}+\mathrm{H})^{+}$calcd. for $\mathrm{C}_{22} \mathrm{H}_{17} \mathrm{~N}_{4} \mathrm{O}_{5}: 417.1815$, found: 417.1823 .

4-(2-(Methylamino)-3-nitro-4,11-dihydropyrano[2,3a]carbazol-4-yl)benzonitrile (11d): Dark brown solid. m.p. 198-200 ${ }^{\circ} \mathrm{C}$; ${ }^{1} \mathrm{H}$ NMR $\left(300 \mathrm{MHz}, \mathrm{DMSO}-d_{6}\right): \delta 11.40(\mathrm{~s}, 1 \mathrm{H}$, $-\mathrm{N} H-), 11010.32(\mathrm{~d}, 1 \mathrm{H}, J=4.5 \mathrm{~Hz},-\mathrm{N} H-), 8.08(\mathrm{~d}, 1 \mathrm{H}, J=$ $7.8 \mathrm{~Hz}, \operatorname{Ar}-H), 7.50(\mathrm{~d}, 2 \mathrm{H}, J=7.8 \mathrm{~Hz}, \mathrm{Ar}-H), 7.45-7.40(\mathrm{~m}$, $3 \mathrm{H}, \mathrm{Ar}-H), 7.35-7.10(\mathrm{~m}, 4 \mathrm{H}, \mathrm{Ar}-H), 5.76(\mathrm{~s}, 1 \mathrm{H},-\mathrm{CH}-)$, $3.26\left(\mathrm{~d}, 3 \mathrm{H}, J=4.5 \mathrm{~Hz},-\mathrm{CH}_{3}\right) ;{ }^{13} \mathrm{C} \mathrm{NMR}\left(75 \mathrm{MHz}, \mathrm{CDCl}_{3}\right): \delta$ 159.1, 146.5, 141.8, 141.3, 139.6, 128.7, 126.0, 125.1, 122.4, 119.6, 119.4, 119.2, 117.4, 115.4, 111.0, 109.9, 109.6, 109.4, 108.8, 107.3, 98.7, 41.2, 28.9; ESIMS: $\mathrm{m} / 2.397(\mathrm{M}+\mathrm{H})^{+}$; HRMS: $m / z(\mathrm{M}+\mathrm{H})^{+}$calcd. for $\mathrm{C}_{23} \mathrm{H}_{17} \mathrm{~N}_{4} \mathrm{O}_{3}: 397.1309$, found: 397.1315 .

4-(3-Methoxyphenyl)-N-methyl-3-nitro-4,11-dihydropyrano[2,3- $a$ ]carbazol-2-amine (11e): Pale brown solid. m.p. 190-192 ${ }^{\circ} \mathrm{C} ;{ }^{1} \mathrm{H}$ NMR $\left(300 \mathrm{MHz}, \mathrm{DMSO}-d_{6}\right): \delta 11.46(\mathrm{~s}, 1 \mathrm{H}$, $-\mathrm{N} H-), 10.38$ (d, $1 \mathrm{H}, J=4.8 \mathrm{~Hz},-\mathrm{NH}-), 8.08(\mathrm{~d}, 1 \mathrm{H}, J=8.4$ $\mathrm{Hz}, \mathrm{Ar}-H), 7.50(\mathrm{~d}, 1 \mathrm{H}, J=7.5 \mathrm{~Hz}, \mathrm{Ar}-H), 7.35(\mathrm{t}, 1 \mathrm{H}, J=7.8$ $\mathrm{Hz}, \mathrm{Ar}-H), 7.30-7.00$ (m, 4H, Ar-H), $6.88(\mathrm{~d}, 2 \mathrm{H}, J=6.9 \mathrm{~Hz}$, $\mathrm{Ar}-H), 6.71(\mathrm{~d}, 1 \mathrm{H}, J=6.9 \mathrm{~Hz}, \mathrm{Ar}-H), 5.87(\mathrm{~s}, 1 \mathrm{H},-\mathrm{CH}-$ ), $3.69\left(\mathrm{~s}, 3 \mathrm{H},-\mathrm{OCH}_{3}\right), 3.24\left(\mathrm{~d}, 3 \mathrm{H}, J=4.8 \mathrm{~Hz},-\mathrm{CH}_{3}\right) ;{ }^{13} \mathrm{C} \mathrm{NMR}$ $\left(75 \mathrm{MHz}, \mathrm{CDCl}_{3}\right): \delta$ 159.2, 159.0, 141.9, 141.4, 141.0, 139.8, 130.2, 126.5, 125.4, 122.6, 119.8, 119.6, 119.4, 119.2, 115.7, 110.5,110.0, 109.7, 108.6, 107.3, 54.9, 41.0, 28.9; ESIMS: $m / z$ 402(M+H) ${ }^{+}$; HRMS: $m / z(\mathrm{M}+\mathrm{H})^{+}$calcd. for $\mathrm{C}_{23} \mathrm{H}_{20} \mathrm{~N}_{3} \mathrm{O}_{4}$ : 402.1406, found: 402.1414

$\mathrm{N}$-Methyl-3-nitro-4-(pyridin-3-yl)-4,11-dihydropyrano[2,3-a] carbazol-2-amine (11f): Dark brown solid. m.p. $>250$ ${ }^{\circ} \mathrm{C} ;{ }^{1} \mathrm{H}$ NMR (300 MHz, DMSO- $\left.d_{6}\right): \delta 11.61$ (s, $1 \mathrm{H},-\mathrm{NH}-$ ), $10.63(\mathrm{~d}, 1 \mathrm{H}, J=4.5 \mathrm{~Hz},-\mathrm{N} H-), 8.64$ (s, $1 \mathrm{H}, \mathrm{Ar}-H), 8.36$ (d, $1 \mathrm{H}, J=4.2 \mathrm{~Hz}, \operatorname{Ar}-H), 8.25(\mathrm{~d}, 1 \mathrm{H}, J=7.8 \mathrm{~Hz}, \mathrm{Ar}-H), 7.66$ (d, $1 \mathrm{H}, J=8.1 \mathrm{~Hz}, \mathrm{Ar}-H), 7.55(\mathrm{~d}, 1 \mathrm{H}, J=7.8 \mathrm{~Hz}, \mathrm{Ar}-H), 7.46(\mathrm{t}$, $1 \mathrm{H}, J=7.8 \mathrm{~Hz}, \mathrm{Ar}-H), 7.35-7.18(\mathrm{~m}, 4 \mathrm{H}, \mathrm{Ar}-H), 5.55(\mathrm{~s}, 1 \mathrm{H}$, $-\mathrm{CH}-$ ), $3.47\left(\mathrm{~d}, 3 \mathrm{H}, J=4.5 \mathrm{~Hz},-\mathrm{CH}_{3}\right) ;{ }^{13} \mathrm{C}$ NMR $(75 \mathrm{MHz}$, $\left.\mathrm{CDCl}_{3}\right)$ : $\delta 164.0,161.3,159.1,146.4,141.5,138.7,136.4,134.1$, 126.5, 126.2, 122.6, 119.7, 119.4, 119.1, 117.3, 114.3, 109.5, 108.8, 107.1, 41.1, 28.9; ESIMS: $m / z 373(\mathrm{M}+\mathrm{H})^{+}$; HRMS: $m / z(\mathrm{M}+\mathrm{H})^{+}$calcd. for $\mathrm{C}_{21} \mathrm{H}_{17} \mathrm{~N}_{4} \mathrm{O}_{3}: 373.1609$, found: 373.1617

Cell cultures, maintenance and antiproliferative evaluation: All cell lines used in this study were purchased from the American Type Culture Collection (ATCC, United States). DU 145, MDA-MB-231, SKOV3, B16-F10 were grown in Dulbecco's modified Eagle's medium (containing $10 \% \mathrm{FBS}$ in ahumidified atmosphere of $5 \% \mathrm{CO}_{2}$ at $37^{\circ} \mathrm{C}$ ). Cells were trypsinized when sub-confluent from T25 flasks/ $60 \mathrm{~mm}$ dishes and seeded in 96-wel plates. The synthesized 
test compounds were evaluated for their in vitro antiproliferative activity in four different cancer cell lines. A protocol of $24 \mathrm{~h}$ continuous drug exposure was used and a MTT cell proliferation assay was used to estimate cell viability or growth. Individual cell lines were grown in their respective media containing $10 \%$ fetal bovine serum and were seeded into 96well microtiter plates in $200 \mu \mathrm{L}$ aliquots at plating densities depending on the doubling time of individual cell lines. The microtiter plates were incubated at $37{ }^{\circ} \mathrm{C}, 5 \% \mathrm{CO}_{2}, 95 \%$ air and $100 \%$ relative humidity for $24 \mathrm{~h}$ prior to addition of experimental drugs. Aliquots of $2 \mu \mathrm{L}$ of the test compounds were added to the wells already containing $198 \mu \mathrm{L}$ of cells, resulting in the required final drug concentrations. For each compound, five concentrations $(0.01,0.1,1,10$ and $100 \mu \mathrm{M})$ were evaluated and each was done in triplicate wells. Plates were incubated further for $24 \mathrm{~h}$ and the assay was terminated by the addition of $10 \mu \mathrm{L}$ of $5 \%$ MTT and incubated for $60 \mathrm{~min}$ at $37{ }^{\circ} \mathrm{C}$. Later, the plates were air-dried. Bound stain was subsequently 60 eluted with $100 \mu \mathrm{L}$ of DMSO and the absorbance was read in multimode plate reader (Varioscan Flash) at a wavelength of $560 \mathrm{~nm}$. Percent growth was calculated on a plate by plate basis for test wells relative to control wells. The above determinations were repeated thrice. The growth inhibitory effects of the 65 compounds were analyzed by generating dose response curves as a plot of the percentage surviving cells versus compound concentration. The sensitivity of the cancer cells to the test compound was expressed in terms of $\mathrm{IC}_{50}$, a value defined as the concentration of compound that produced $50 \%$ reduction as 70 compared to the control absorbance. $\mathrm{IC}_{50}$ values are indicated as means $\pm \mathrm{SD}$ of three independent experiments.

Molecular modelling: The docking studies were performed using Glide (Schrodinger) and the favourable interactions between ligand molecule with receptor were analyzed. The PDB ID 3E22 was used for docking study which was downloaded from protein data bank site (www.rcsb.org). The protein was refined by using protein 80 preparation wizard procedure available with maestro suite of Schrodinger software (Maestro, Schrodinger, LLC, New York, NY, 2017). This is carried out to release any unwanted strain in crystal structure of the protein and to add the missing hydrogens in the protein and assign all bond orders in correct format.

Ligand preparation: All ligands were drawn by using maestro interface of Schrodinger software by edit-build structure protocol. The valency of all ligands cross checked and minimized by macromodel minimization and optimized the structures. Those 90 optimized structures further processed by using ligprep protocol to get stable confirmation, which will be ready for docking. The output structure was used for docking study.

Grid generation and docking process: The grid generation 95 and docking performed through preprocess optimization and minimization. All ligands were drawn by using maestro software and prepared for docking by ligprep module (LigPrep, Schrodinger, LLC, New York, NY, 2017). Docking of the ligands performed through Glide program by applying XP scoring 100 function. The docking protocol in this study was obtained using OPLS 2005 all-atom force field. Glide uses an explicit water model for modelling salvation effects.
The demonstrated research output and results are the structural model exploration and involved methodology is very effective. In this methodology we 105 taken G-score, which is a modified and extended empirical scoring function based on Chem-Score the docking method that is XP descriptors been used to score (G-score) for ligand includes drug like properties such as LipoEvdW, H-bond and RotPenal. Lipo-EvdW is the Chem-Score lipophilic pair term and fraction 110 of the total receptor-ligand vdw's energy.

\section{RESULTS AND DISCUSSION}

Initially, a one-pot three-component reaction using equimolecular amount of 4-hydroxycarbazole (6), aromatic aldehyde (7) and (E)-N-methyl-1-(methylthio)-2-nitro-ethenamine (8) were chosen as the model reaction for the construction of pyranocarbazole derivatives (9a) (Scheme-I).

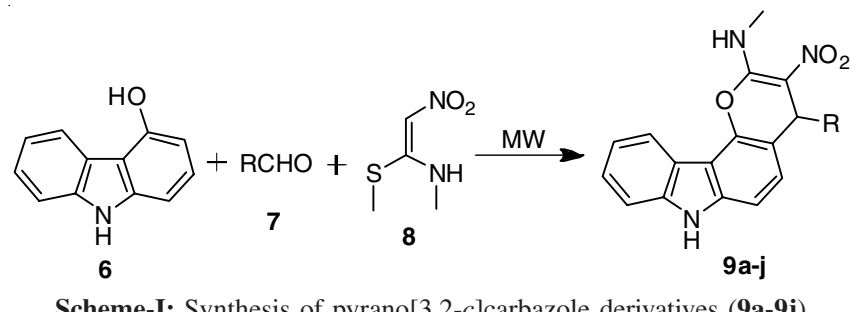

Scheme-I: Synthesis of pyrano[3,2-c]carbazole derivatives (9a-9j)

In order to find optimized conditions the model reaction was performed in ethanol which failed to yield the product even after $24 \mathrm{~h}$ either at ambient temperature or reflux conditions (Table-1, entry 1-2). Then the reaction was then tested in the presence of bases such as triethylamine, pyridine and DMAP in different solvents (Table-1, entries 3-5) but these bases could not promote the reaction efficiently even at prolonged reaction times. However, when the reaction carried out under neat conditions at $100{ }^{\circ} \mathrm{C}$ without any base, it was gratifying to discover that reaction completed within $3 \mathrm{~h}$ with the yield of N-methyl-3-nitro-4-phenyl-4,7-dihydropyrano-[3,2c] carbazol-2-amine (9a) (64\%, Table-1, entry 6). Inspired by this result, the model reaction was further investigated in the absence of solvent under microwave irradiation at $360 \mathrm{~W}$ for 5 min, which led to formation of product $9 \mathbf{a}$ in $89 \%$ yield (Table-1, entry 7). Next we tried $540 \mathrm{~W}$ and the product 9a was obtained in $70 \%$ yield (Table-1, entry 8 ). Further increment of reaction time or radiation power to $720 \mathrm{~W}$ led to a 40 decrease in yield (Table-1, entry 9, 10). Hence, we selected 360 $\mathrm{W}$ for all subsequent reactions. Further, the method does not require column chromatographic purification for isolation of the products. After completion of the reaction, the precipitated solid was filtered and washed with ethanol to give the pure pyranocarbazole without the need for column chromatography.

With optimized conditions in hand we focused on the scope of this method with various substituted aromatic aldehydes (Table-2). It was observed that benzaldehydes bearing electron withdrawing groups such as $\mathrm{F}, \mathrm{CN}, \mathrm{CF}_{3}$ and $\mathrm{NO}_{2}$ groups exhibited good reactivity in the reaction and gave the corresponding pyrano[3,2-c]carbazole derivatives in good yields (Table-2). In addition, electron-donating OMe group was also favourable for the transformation $(\mathbf{9 g}-\mathbf{h})$. The reaction 


\begin{tabular}{cccccc}
\hline \multicolumn{7}{c}{ TABLE-1 } \\
\multicolumn{7}{c}{ OPTIMIZATION OF REACTION CONDITIONS FOR } \\
THE SYNTHESIS OF PYRANO[3,2-c]CARBAZOLE \\
DERIVATIVES (9a) \\
\hline \multirow{5}{*}{ Entry } & Solvent & Base & Temp. $\left({ }^{\circ} \mathrm{C}\right)$ & Time & $\begin{array}{c}\text { Yield } \\
(\%)\end{array}$ \\
\hline 1 & Ethanol & - & RT & $24 \mathrm{~h}$ & - \\
2 & Ethanol & - & Reflux & $24 \mathrm{~h}$ & 85 \\
3 & Ethanol & TEA & Reflux & $24 \mathrm{~h}$ & 56 \\
4 & Toluene & Pyridine & Reflux & $12 \mathrm{~h}$ & 94 \\
5 & CH $_{3} \mathrm{CN}$ & DMAP & Reflux & $10 \mathrm{~h}$ & - \\
6 & - & - & $100{ }^{\circ} \mathrm{C}$ & $3 \mathrm{~h}$ & 64 \\
7 & - & - & MW. 360 W & $5 \mathrm{~min}$ & 89 \\
8 & - & - & MW. 540 W & $5 \mathrm{~min}$ & 70 \\
9 & - & - & MW. 720 W & $5 \mathrm{~min}$ & 49 \\
10 & - & - & MW. 360 W & $10 \mathrm{~min}$ & 74 \\
\hline
\end{tabular}

TABLE-2

SYNTHESIS OF PYRANO[2,3- $a$ ]CARBAZOLE DERIVATIVES (9a-j) UNDER OPTIMIZED CONDITIONS

\begin{tabular}{|c|c|c|}
\hline Compound No. & $\mathrm{R}$ & Yield (\%) \\
\hline 9a & $\mathrm{C}_{6} \mathrm{H}_{5}$ & 89 \\
\hline 9b & $4-\mathrm{F}-\mathrm{C}_{6} \mathrm{H}_{4}$ & 82 \\
\hline $9 \mathrm{c}$ & $2-\mathrm{NO}_{2}-\mathrm{C}_{6} \mathrm{H}_{4}$ & 83 \\
\hline 9d & $4-\mathrm{CN}-\mathrm{C}_{6} \mathrm{H}_{4}$ & 78 \\
\hline $9 e$ & $4-\mathrm{CF}_{3}-\mathrm{C}_{6} \mathrm{H}_{4}$ & 81 \\
\hline 9f & $4-\mathrm{OH}-\mathrm{C}_{6} \mathrm{H}_{4}$ & 75 \\
\hline $9 \mathrm{~g}$ & $4-\mathrm{OCH}_{3}-\mathrm{C}_{6} \mathrm{H}_{4}$ & 69 \\
\hline $9 \mathrm{~h}$ & $3,4,5-\left(\mathrm{OCH}_{3}\right)_{3}-\mathrm{C}_{6} \mathrm{H}_{2}$ & 76 \\
\hline $9 \mathrm{i}$ & 4-Isopropyl- $\mathrm{C}_{6} \mathrm{H}_{4}$ & 79 \\
\hline 9j & 3-Phenylpyridine & 77 \\
\hline
\end{tabular}

was also quite successful with heteroaryl 3-pyridinecarboxaldehyde afford the corresponding pyrano[3,2-c]carbazole derivative in $76 \%$ yield (Table-2, entry 9j). However, aliphatic aldehydes such as acetaldehyde, propionaldehyde did not participate in the reaction. The products were characterized by ${ }^{1} \mathrm{H},{ }^{13} \mathrm{C}$ NMR, IR and mass spectroscopic analyses.

Initially, Knoevenagel condensation reaction of 4-hydroxy carbazole (6) and benzaldehyde (7) affords adduct (A). Then the adduct $\mathbf{A}$ upon Michael-type addition with (E)-N-methyl1-(methylthio)-2-nitroethenamine (8) affords the open-chain intermediate (B). The intermediate (B) apparently tautomerized to another intermediate $(\mathbf{C})$ via an imine-enamine tautomerism. Finally, the intermediate $(\mathbf{C})$ undergoes intramolecular ocyclization to form (9a) through the elimination of MeSH.

Encouraged by the above results, next we have focused our attention on synthesis of pyrano[2,3- $a$ ] derivatives between the 2-hydroxycabazole (10) aromatic substituted aldehydes (7) and (E)-N-methyl-1-(methylthio)-2-nitroethenamine (8) under optimized conditions. For instance, three component coupling of 2-hydroxycarbazole (10), benzaldehyde (7) and (E)-N-methyl-1-(methylthio)-2-nitroethenamine (8) under MW irradiation afford. The corresponding N-methyl-3-nitro4-phenyl-4,11-dihydropyrano [2,3-a]carbazol-2-amine (11a) in $76 \%$ yield. Bromo, nitro-, cyano- and methoxy substituted aromatic aldehydes also participated well in the one-pot three component coupling reactions and the corresponding pyrano[2,3- $a]$ carbazoles (11b-e) were obtained in good yields (SchemeII). The reaction was also quite successful with heterocyclic 3-pyridine carboxaldehyde (Table-3, entry 11f).

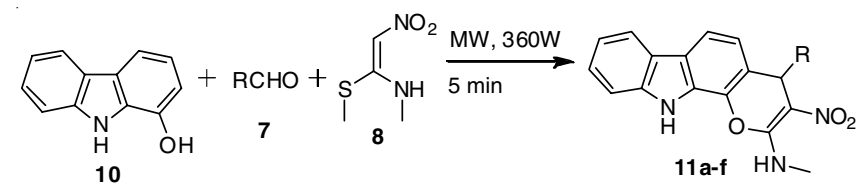

Scheme-II: Synthesis of pyrano[2,3-a]carbazole derivatives (11a-f) under optimized conditions

\begin{tabular}{ccc}
\multicolumn{4}{c}{ TABLE-3 } \\
SYNTHESIS OF PYRANO[2,3- $a$ ]CARBAZOLE \\
DERIVATIVES (11a-f) UNDER OPTIMIZED CONDITIONS \\
\hline \multicolumn{1}{c}{ Compound No. } & \multicolumn{1}{c}{$\mathrm{R}$} & Yield (\%) \\
\hline 11a & $\mathrm{C}_{6} \mathrm{H}_{5}$ & 76 \\
$\mathbf{1 1 b}$ & $4-\mathrm{Br}_{-} \mathrm{C}_{6} \mathrm{H}_{4}$ & 68 \\
$\mathbf{1 1}$ & $4-\mathrm{NO}_{2}-\mathrm{C}_{6} \mathrm{H}_{4}$ & 70 \\
11d & $4-\mathrm{CN}_{-} \mathrm{C}_{6} \mathrm{H}_{4}$ & 67 \\
11e & 3-OCH $-\mathrm{C}_{6} \mathrm{H}_{4}$ & 71 \\
11f & 3-Phenylpyridine & 66 \\
\hline
\end{tabular}

Antiproliferative activity: To investigate the anticancer activities of the synthesized compounds, we have evaluated antiproliferative activities of all synthesized compounds $\mathbf{9 a - j}$ and 11a-f by an in vitro assay on four cancer cell lines belonging to different tumor types such as DU 145 (prostate cancer), MDA-MB-231 (breast cancer), SKOV3 (ovarian cancer) and B16-F10 (skin cancer). Results are expressed as $\mathrm{IC}_{50}$ values (Table-4) the concentration at which a compound causes $50 \%$ cell death with respect to a control culture. A well known anticancer agent Doxorubicin was used as a reference compound in this assay [45].

As illustrated in Table-4, pyrano[3,2-c]carbazoles (9a-j) exhibited more potent antiproliferative activity than the pyrano[2,3-a]carbazoles (11a-f) against the four tested cancer cell lines. Further studies reveal that trimethoxyphenyl substituted pyrano[3,2-c]carbazole (9h) exhibited most potent antriproliferative activity in comparison with other compounds in all the four cancer cell lines (Table-4). From the in vitro antipro-

\begin{tabular}{|c|c|c|c|c|}
\hline \multicolumn{5}{|c|}{$\begin{array}{c}\text { TABLE-4 } \\
\text { ANTIPROLIFERATIVE ACTIVITY OF } \\
\text { PYRANO[3,2- } c \text { CARBAZOLE DERIVATIVES(9a-j) } \\
\text { AND PYRANO[2,3- } a \text { ]CARBAZOLE (11a-f) DERIVATIVES } \\
\text { ON VARIOUS CANCEROUS CELL LINES }\end{array}$} \\
\hline \multirow{2}{*}{ Compd. } & \multicolumn{4}{|c|}{$\mathrm{IC}_{50}(\mu \mathrm{M})$} \\
\hline & DU145 & MDAMB231 & SKOV3 & B16-F10 \\
\hline $9 a$ & $7.2 \pm 0.38$ & $7.9 \pm 0.42$ & $11.8 \pm 0.46$ & $19.4 \pm 0.49$ \\
\hline $9 b$ & $14.5 \pm 0.56$ & $6.8 \pm 0.37$ & $6.3 \pm 0.35$ & $8.4 \pm 0.66$ \\
\hline $9 c$ & $23.0 \pm 0.42$ & $18.6 \pm 0.54$ & $15.9 \pm 0.59$ & $10.0 \pm 0.58$ \\
\hline 9d & $27.1 \pm 0.51$ & NA & $11.8 \pm 0.61$ & $22.4 \pm 0.47$ \\
\hline $9 e$ & $17.8 \pm 0.47$ & $11.3 \pm 0.65$ & $12.6 \pm 0.48$ & $21.0 \pm 0.66$ \\
\hline 9f & NA & NA & $21.9 \pm 0.53$ & $19.8 \pm 0.58$ \\
\hline $9 \mathrm{~g}$ & $13.7 \pm 0.56$ & $23.5 \pm 0.54$ & $13.7 \pm 0.72$ & $23.7 \pm 0.49$ \\
\hline $9 \mathrm{~h}$ & $8.4 \pm 0.44$ & $5.7 \pm 0.41$ & $5.1 \pm 0.37$ & $9.5 \pm 0.48$ \\
\hline $9 \mathrm{i}$ & $17.1 \pm 0.57$ & $9.9 \pm 0.40$ & $17.0 \pm 0.68$ & $25.5 \pm 0.66$ \\
\hline 9j & $16.3 \pm 0.53$ & $59.8 \pm 0.62$ & $19.2 \pm 0.75$ & $13.2 \pm 0.57$ \\
\hline 11a & $9.1 \pm 0.39$ & $14.0 \pm 0.38$ & $9.2 \pm 0.88$ & $18.3 \pm 0.62$ \\
\hline 11b & $47.1 \pm 0.58$ & $33.2 \pm 0.55$ & $23.4 \pm 0.64$ & $22.5 \pm 0.83$ \\
\hline $11 \mathrm{c}$ & $37.8 \pm 0.62$ & $44.9 \pm 0.62$ & $19.1 \pm 0.54$ & $30.3 \pm 0.76$ \\
\hline 11d & $61.1 \pm 0.73$ & $53.3 \pm 0.87$ & $17.3 \pm 0.67$ & $22.3 \pm 0.48$ \\
\hline $11 \mathrm{e}$ & $29.4 \pm 0.68$ & NA & $17.1 \pm 0.48$ & $34.5 \pm 67$ \\
\hline $11 f$ & $41.2 \pm 0.56$ & $29.9 \pm 0.67$ & $10.8 \pm 0.76$ & NA \\
\hline DA & $0.7 \pm 0.19$ & $0.7 \pm 0.25$ & $0.8 \pm 0.24$ & $2.0 \pm 0.53$ \\
\hline
\end{tabular}


liferative activity data, a preliminary structure-activity relationship of the synthesized compounds was studied.

Among the pyrano[3,2-c]carbazole compounds, compound 9a exhibited significant growth inhibitory activity against DU145 and MDA-MB-231 with IC $_{50}$ values of $7.2 \mu \mathrm{M}$ and $7.9 \mu \mathrm{M}$. To study the effect of substitution on the phenyl ring, flouro, nitro, cyano, hydroxy, isopropyl and methoxy groups were introduced in the ortho, para and meta positions. Compound $9 \mathbf{b}$ with fluoro substitution on phenyl ring exhibited good inhibition with $\mathrm{IC}_{50}$ values of $6.8 \mu \mathrm{M}$ against breast cancer, $6.3 \mu \mathrm{M}$ against ovarian cancer and $8.4 \mu \mathrm{M}$ against skin cancer cell lines. This could be attributed to the presence of huge electron density around the fluorine substituent on the phenyl ring. Compound $9 \mathrm{c}$ with strong electron-withdrawing substituent $\left(\mathrm{NO}_{2}\right)$ exhibited its efficacy against skin cancer cells. Whereas, in case of compounds $9 \mathbf{d}$ and $9 \mathbf{e}$ the presence of cyano and trifluoromethyl groups on the phenyl ring might responsible for hindering their cytotoxicity when compared with compounds $\mathbf{9 a}$ and $\mathbf{9 b}$. On the other hand, hydroxyphenyl substituted compound $\mathbf{9}$ exhibited lower activities than others. Interestingly, trimethoxyphenyl substituted pyrano[3,2-c]carbazole compound $9 \mathrm{~h}$ was more active with $\mathrm{IC}_{50}$ values of $8.4 \mu \mathrm{M}$ against DU145, 5.7 $\mu \mathrm{M}$ against MDAMB231, 5.1 $\mu \mathrm{M}$ against SKOV3, 9.5 $\mu \mathrm{M}$ against B16-F10, respectively in their antiproliferative activity. It is obvious that the 3,4,5-trimethoxy groups in the phenyl ring of the compound $\mathbf{9 h}$ are responsible for increase the cytotoxicity. However, mono methoxy substituted compound $\mathbf{9 g}$ displayed moderate activities with $\mathrm{IC}_{50}$ values of $13.7 \mu \mathrm{M}$ against both prostate cancer and ovarian cancer cell lines. The effect of isopropyl group on phenyl ring of compound $9 \mathbf{i}$ was observed significant inhibition of the growth of breast cancer cell line with $\mathrm{IC}_{50}$ value of $9.9 \mu \mathrm{M}$. These data indicated that compounds containing electron donating methoxy substituent on phenyl ring showed enhanced activity compared to compounds containing electron withdrawing substituents $\left(\mathrm{NO}_{2}, \mathrm{CN}, \mathrm{CF}_{3}\right)$. To further elucidate the structure activity relationships, the phenyl ring was extensively modified with pyridine ring in compound $\mathbf{9 j}$, which exhibited reduced cytotoxicity in all the tested cell lines.

Among pyrano[2,3-a]pyranocarbazole derivatives compound 11a displayed significant $\mathrm{IC}_{50}$ value of $9.1 \mu \mathrm{M} 5$ against prostate cancer and $9.2 \mu \mathrm{M}$ against ovarian cancer cell lines. All other substitutions on the phenyl ring that were tested, including bromo, nitro, cyano, methoxy groups (11b-e) decreased the activity substantially compared to the corresponding compound 11a.Overall, our current activity data suggested that compounds $9 \mathrm{a}, 9 \mathrm{~b}, 9 \mathrm{~h}$ and 11a presented in this study have good anti-cancer properties. Trimethoxy groups in the phenyl ring are essential for potent cytotoxicity. These initial studies will definitely help in identifying the lead molecules with anticancer properties and these studies are currently underway in our laboratory.

Molecular modeling: In order to rationalize the experimental results obtained, molecular docking studies were perfor-
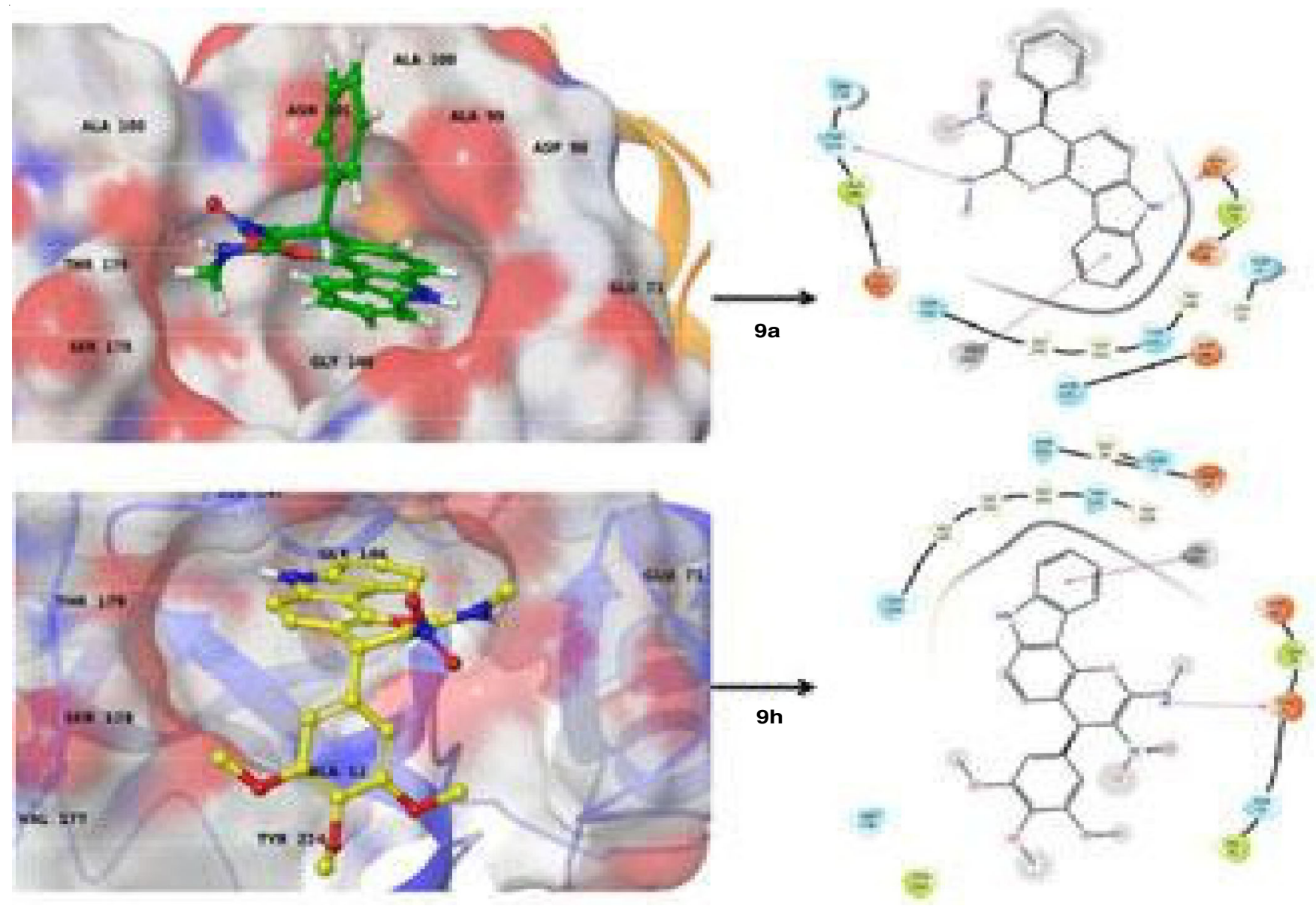

Fig. 1. 
med on representative compounds like $9 \mathbf{a}, 9 \mathbf{b}$ and $9 \mathbf{h}$ against tubulin structures. Glide docking has been employed and the lead compounds docked in the colchicines binding pocket of tubulin (PDB code: 3E22).

The results of molecular docking are depicted in Fig. 1. It is well studied that colchicine binding site is generally present at the interface of $\alpha, \beta$-tubulin heterodimers [46,47]. The lead compounds used for the docking study are shown as different colours of ball and stick model and hydrogen bonds are shown as blue coloured dots.

Docking simulations showed that compound 9a was surrounded by the amino acid residues like Ser178, Thr 179, Ala 180, Glu 183, Ser 140, Gly 143, Gly 144, Thr 145, Gly146, Ash69, Leu70 and Glu71. In addition, the carbazole ring NH involved in hydrogen bonging with Glu71 residue and methyl substituted NH formed hydrogen bonding interaction with Thr179 residue. Binding is seen to be stabilized by hydrogen bonding. Similar results were observed in compound $\mathbf{9 b}$. Compound $9 \mathrm{~b}$ also shows two significant hydrogen bonding interactions with amino acid residues Glu71 and Thr179.

Whereas, compound $9 \mathrm{~h}$ made hydrophobic interactions with amino acid residues like Ser140, Gly142, Gly143, Gly144, Thr145, Gly146, Ash69, Leu70, Glu71, Thr73, Thr73, Val74, Tyr224 and Ser178. Additionally, there is hydrogen bonding interaction between compound $9 \mathrm{~h}$ with Glu71 residue of the target protein. Indeed, Ser178 and Tyr 224 amino acid residues of $\beta$-tubulin formed significant hydrophobic interactions with the trimethoxyphenyl moiety of $\mathbf{9 h}$ appeared to stabilize the ligand in the active site. Therefore, these docking simulations suggested that the ligands bind to the active site effectively. The results obtained are in agreement and further strengthened with in vitro antiproliferative activity.

\section{Conclusion}

In conclusion, the present work reports a simple and efficient one-pot three-component protocol for the expedient synthesis of novel pyrano[3,2-c]carazoles and pyrano[2,3- $a$ ]carbazole derivatives in good yields. It is noteworthy that this reaction results in the formation of three new bonds (two $\mathrm{C}-\mathrm{C}$ and one $\mathrm{C}-\mathrm{O}$ ) in a single operation. The significant advantages of this protocol include catalyst free, solvent free, readily available substrates, short reaction time, atom-economy and no column chromatographic purification. These advantages make this methodology facile and appropriate to create diverse libraries. Screening of all sixteen new pyranocarbazole derivatives against cancer cell lines DU 145, MDA-MB-231, SKOV3 and B16F10 revealed that synthesized compounds displayed moderate to potent antiproliferative activity. Structure-activity studies indicated that trimethoxyphenyl substituted pyrano[3,2$c$ carbazole derivative $\mathbf{9 h}$ displayed the most potent antiproliferative activity against the four-cell lines. In addition,the in silico molecular docking results supported the in vitro studies. These results may be helpful for the future design of structurally related tubulin inhibitors.

\section{CONFLICT OF INTEREST}

The authors declare that there is no conflict of interests regarding the publication of this article.

\section{REFERENCES}

1. A.W. Schmidt, K.R. Reddy and H.J. Knolker, Chem. Rev., 112, 3193 (2012); https://doi.org/10.1021/cr200447s.

2. H.J. Knolker and K.R. Reddy, Chem. Rev., 102, 4303 (2002); https://doi.org/10.1021/cr020059j.

3. H.J. Knolker, Curr. Chem., 244, 115 (2005); https://doi.org/10.1007/b96890.

4. H.J. Knolker, K.R. Reddy and G.A. Cordell, The Alkaloids, Academic Press: London, pp. 1-430 (2008).

5. F.A. Tanious, W.D. Wilson, D.A. Patrick, R.R. Tidwell, P. Colson, C. Houssier, C. Tardy and C. Bailly, Eur. J. Biochem., 268, 3455 (2001); https://doi.org/10.1046/j.1432-1327.2001.02242.x.

6. C.C. Chang, I.C. Kuo, J.J. Lin, Y.C. Lu, C.T. Chen, H.T. Back, P.J. Lou and T.C. Chang, Chem. Biodivers., 1, 1377 (2004); https://doi.org/10.1002/cbdv.200490100.

7. M.J. Hsu, Y. Chao, Y.H. Chang, F.M. Ho, Y.L. Huang, L.J. Huang, T.Y. Luh, C.P. Chen and W.W. Lin, Biochem. Pharmacol., 70, 102 (2005); https://doi.org/10.1016/j.bcp.2005.04.014.

8. A.R. Howard-Jones and C.T. Walsh, J. Am. Chem. Soc., 128, 12289 (2006); https://doi.org/10.1021/ja063898m.

9. L. Hu, Z. Li, Y. Li, J. Qu, Y.H. Ling, J. Jiang and D.W. Boykin, J. Med. Chem., 49, 6273 (2006); https://doi.org/10.1021/jm060546h.

10. R.S. Ramsewak, M.G. Nair, G.M. Strasburg, D.L. DeWitt and J.L. Nitiss, J. Agric. Food Chem., 47, 444 (1999); https://doi.org/10.1021/jf9805808.

11. I. Mester and J. Reisch, Ann. Chem., 10, 1725 (1977); https://doi.org/10.1002/jlac.197719771019.

12. S. Syam, A.B. Abdul, M.A. Sukari, S. Mohan, S.I. Abdelwahab and T.S. Wah, Molecules, 16, 7155 (2011); https://doi.org/10.3390/molecules16087155.

13. C.B. Cui, S.Y. Yan, B. Cai and X.S. Yao, J. Asian Nat. Prod. Res., 4, 233 (2002); https://doi.org/10.1080/1028602021000049041.

14. Y. Tachibana, H. Kikuzaki, L.H. Lajis and N. Nakatani, J. Agric. Food Chem., 51, 6461 (2003); https://doi.org/10.1021/jf034700+.

15. M. Itoigawa, Y. Kashiwada, C. Ito, H. Furukawa, Y. Tachibana, K.F. Bastow and K.-H. Lee, J. Nat. Prod., 63, 893 (2000); https://doi.org/10.1021/np000020e.

16. C. Ito, M. Itoigawa, A. Sato, C.M. Hasan, M.A. Rashid, H. Tokuda, T. Mukainaka, H. Nishino and H. Furukawa, J. Nat. Prod., 67, 1488 (2004); https://doi.org/10.1021/np0400611.

17. C. Ito, S. Katsuno, M. Itoigawa, N. Ruangrungsi, T. Mukainaka, M. Okuda, Y. Kitagawa, H. Tokuda, H. Nishino and H. Furukawa, J. Nat. Prod., 63, 125 (2000); https://doi.org/10.1021/np990285x.

18. C. Ito, S. Katsuno, N. Ruangrungsi and H. Furukawa, Chem. Pharm. Bull. (Tokyo), 46, 344 (1998); https://doi.org/10.1248/cpb.46.344.

19. K. Prasad and O. Revu, Synthesis, 44, 2243 (2012); https://doi.org/10.1055/s-0031-1291154.

20. K. Prabakaran, M. Zeller and K.J.R. Prasad, Synlett, 13, 1835 (2011); https://doi.org/10.1055/s-0030-1260965.

21. K.K. Gruner, T. Hopfmann, K. Matsumoto, A. Jager, T. Katsuki and H.J. Knolker, Org. Biomol. Chem., 9, 2057 (2011); https://doi.org/10.1039/c0ob01088j.

22. M. Sridharan and K.J.R. Prasad, Z. Naturforsch. B, 63, 1112 (2008); https://doi.org/10.1515/znb-2008-0916.

23. R. Hesse, K.K. Gruner, O. Kataeva, A.W. Schmidt and H.-J. Knölker, Chem. Eur. J., 19, 14098 (2013); https://doi.org/10.1002/chem.201301792.

24. V.P. Kumar, K.K. Gruner, O. Kataeva and H.J. Knolker, Angew. Chem. Int. Ed., 52, 11073 (2013); https://doi.org/10.1002/anie.201305993.

25. R. Hesse, A. Jager, A.W. Schmidt and H.J. Knolker, Org. Biomol. Chem., 12, 3866 (2014); https://doi.org/10.1039/C4OB00367E.

26. K.K. Julich-Gruner, O. Kataeva, A.W. Schmidt and H.J. Knolker, Chem. Eur. J., 20, 8536 (2014); https://doi.org/10.1002/chem.201403143. 
27. R. Hesse, O. Kataeva, A.W. Schmidt and H.J. Knolker, Chem. Eur. J., 20, 9504 (2014); https://doi.org/10.1002/chem.201403645.

28. C. Gassner, R. Hesse, A.W. Schmidt and H.J. Knolker, Org. Biomol. Chem., 12, 6490 (2014); https://doi.org/10.1039/C4OB01151A.

29. R. Hesse, A.W. Schmidt and H.J. Knolker, Tetrahedron, 71, 3485 (2015); https://doi.org/10.1016/j.tet.2015.03.064.

30. C. Schuster, K.K. Julich-Gruner, H. Schnitzler, R. Hesse, A. Jager, A.W. Schmidt and H.J. Knolker, J. Org. Chem., 80, 5666 (2015); https://doi.org/10.1021/acs.joc.5b00630.

31. C. Schuster, M. Ronnefahrt, K.K. Julich-Gruner, A. Jager, A.W. Schmidt and H.J. Knolker, Synthesis, 48, 150 (2016); https://doi.org/10.1055/s-0035-1560359.

32. T. Wang and T.R. Hoye, J. Am. Chem. Soc., 138, 13870 (2016); https://doi.org/10.1021/jacs.6b09628.

33. W. Zhang, J. Wang, J. Mao, L. Hu, X. Wu and C. Guo, Tetrahedron Lett., 57, 1985 (2016); https://doi.org/10.1016/j.tetlet.2016.03.081.

34. K.R. Reddy, A.S. Reddy, D.K. Dhaked, S.K. Rasheed, A.S. Pathania, R. Shankar, F. Malik and P. Das, Org. Biomol. Chem., 13, 9285 (2015); https://doi.org/10.1039/C5OB01295C.

35. Y. Liu, Y. Guo, F. Ji, D. Gao, C. Song and J. Chang, J. Org. Chem., 81, 4310 (2016); https://doi.org/10.1021/acs.joc.6b00729.

36. S. Kotha, R. Ali and M. Saifuddin, Tetrahedron, 71, 9003 (2015); https://doi.org/10.1016/j.tet.2015.09.044.

37. S. Hou, Y. Liu, Y. Kong and M.L. Brown, Org. Lett., 17, 2298 (2015); https://doi.org/10.1021/acs.orglett.5b00422.
38. P. Padmaja, G. Koteswara Rao, A. Indrasena, B.V. Subba Reddy, N. Patel, A.B. Shaik, N. Reddy, P.K. Dubey and M.P. Bhadra, Org. Biomol. Chem., 13, 1404 (2015); https://doi.org/10.1039/C4OB02015D.

39. P. Padmaja, B.V.S. Reddy, N. Jain, S.R. Mutheneni, P. Bollepelli, S. Polepalli, G. Rambabu and P.N. Reddy, New J. Chem., 40, 8305 (2016); https://doi.org/10.1039/C6NJ01580H.

40. P.N. Reddy, P. Padmaja, B.R. Reddy, G. Rambabu and M.P. Kumar, Med. Chem. Res., 25, 2093 (2016); https://doi.org/10.1007/s00044-016-1676-x.

41. P.N. Reddy, P. Padmaja, B.R. Reddy and S.S. Jadav, Med. Chem. Res., 26, 2243 (2017); https://doi.org/10.1007/s00044-017-1927-5.

42. P. Padmaja and N. Reddy, Curr. Org. Synth., 12, 3 (2015); https://doi.org/10.2174/1570179411666140806005540.

43. P.N. Reddy and P. Padmaja, ARKIVOC, 244 (2015); https://doi.org/10.3998/ark.5550190.p008.822.

44. P. Padmaja and P.N. Reddy, Lett. Org. Chem., 14, 115 (2017); https://doi.org/10.2174/1570178614666170123123526.

45. P. Prasad, A. Shuhendler, P. Cai, A.M. Rauth and X.Y. Wu, Cancer Lett., 334, 263 (2013); https://doi.org/10.1016/j.canlet.2012.08.008

46. Y. Lu, J. Chen, M. Xiao, W. Li and D.D. Miller, Pharm. Res., 29, 2943 (2012); https://doi.org/10.1007/s11095-012-0828-z.

47. A. Dorléans, B. Gigant, R.B.G. Ravelli, P. Mailliet, V. Mikol and M. Knossow, Proc. Natl. Acad. Sci. (USA), 106, 13775 (2009); https://doi.org/10.1073/pnas.0904223106. 